\title{
Local aspects of UK renewable energy development: \\ Exploring public beliefs and policy implications
}

\author{
Dr. Patrick Devine-Wright BA MSc CPsychol
}

Senior Research Fellow in Environmental Psychology, Institute of Energy and Sustainable Development, De Montfort University, Queen's Building, The Gateway, Leicester LE1 9EH

Tel: 01162577970 Fax: 01162577981 Email: pdwright@dmu.ac.uk

\section{Summary:}

Despite several recent UK initiatives to promote renewable energy development at the local level, little research has been carried out to investigate public beliefs about aspects of local renewable energy development. This research attempted to address this gap. Empirical data was collected at the Awel Aman Tawe development in South Wales immediately before and after a public participation process. The results indicate that support for specific aspects of local energy development (partnership with local communities, local use of generated energy and profits put back into the local community) were consistently high across time, with support for local ownership at a slightly lower level, yet still high. Secondly, socio-demographical analyses indicated that personal factors such as respondents' age, gender and employment status were important in shaping several of these beliefs. Since UK renewable energy development has often been controversial and subject to delay, results suggest that the adoption of a locally embedded development approach by public and private sector stakeholders will be strongly supported by local people. The implications of the results are discussed in relation to existing industry best practice guidelines and recent policy initiatives.

\section{Introduction:}

In the UK, in contrast to other EU countries such as Denmark and Sweden, few examples of renewable energy development with high levels of local involvement or leadership exist. Development has tended to be private-sector led and driven by economic and environmental rather than social concerns (Hinshelwood, 2000; Devine-Wright, McAlpine and Batley-White, 2001). At the same time, controversy has frequently arisen over new development, with many proposals stalled or refused at the planning stage leading to slow rates of development. For example, in England during the period June 1999 until May 2000, only 24.8\% of planning applications for wind farms had been accepted, with $26.6 \%$ rejected and $41 \%$ under inquiry (Renew, 2002). This has led to concern about the feasibility of government targets aiming to achieve $10 \%$ of electricity supplied from renewable sources by 2010 (Department of Trade and Industry, 1999). 
Growing concern has led many to question the conventional energy development approach and to propose mechanisms for enabling local communities to become better informed about, and more closely involved in, energy development in their locality. For example, it has been suggested that "local energy end-users could and should participate in energy planning and their grasp of energy issues as end-users coupled with their knowledge of local conditions - needs to be fully integrated into the decision making process" (Fielden, 2000, page 45). This view was echoed in several recent policy statements by expert institutions. For example, the Local Government Association (1999) has called for community planning and LA21 practices to be applied to local energy planning. The Royal Commission on Environmental Pollution (2000) recommended that every UK community should review its impact upon the environment in terms of its demand for energy, and the ways in which these demands can be met. A more locally embedded approach was intrinsic to the 'local stewardship' energy scenario created by a recent Foresight exercise and taken up in the PIU Energy Review (PIU, 2002) and the area-based carbon reduction approach promoted by the Sustainable Development Commission (Devine-Wright, Fleming, Akehurst, Kersey \& Jamison, 2003). Finally, the Energy White Paper (2003) called for 'greater involvement from local communities' (page 16) in the future UK energy system.

In terms of practice, it is the distinctive element of several recent UK voluntary, private and public sector initiatives. These include the Community Renewables Initiative developed by the Countryside Agency that aims to enable new renewable energy schemes in England that are supported by local communities; Community Action for Energy, funded by the Energy Savings Trust that aims to boost community involvement in energy efficiency projects; WindWorks, promoted by the business National Wind Power aimed at farmers and landowners and Solar Clubs, promoted by voluntary organisations (e.g. Environ and the Centre for Sustainable Energy) which aims to enable local people to install solar energy systems. Finally, the 'Clear Skies' initiative providing capital funding for renewable energy systems and feasibility studies for community projects was launched by the Department of Trade and Industry in early 2003.

This increasingly popular political and practical focus upon energy, particularly renewable energy, at local level in the UK is not a new idea, but harks back to the 'soft energy path' advocated by Lovins in the 1970s (Lovins, 1977), to advocates of small-scale development (Schumacher, 1974) and appropriate technology (Dunn, 1978). It is similar to the development approach adopted by some European countries for wind and biomass (e.g. Denmark: Daugaard, 1997; and Austria: Rakos, 1998) in promoting more localised development approaches through co-operative structures. It is also similar to many solar, biomass and mini-hydro projects in developing countries that are often off-grid and village-scale (e.g. Schweizer-Ries, Casper, Djuwita, Ramirez \& de Avila, 2001). As these examples illustrate, the local energy approach is not necessarily intrinsic to any specific energy resource or to any specific scale of energy technology development, large or small.

It contrasts with the supply-led energy system that was devised in the US and UK in the mid- $20^{\text {th }}$ century before concerns about global warming arose, which was oriented towards the utilisation of fossil-fuels and nuclear energy, and which was focused upon 
stimulating consumer demand (Patterson, 1999). A centralised infrastructure deliberately creates a spatial, and consequently psychological, distance between energy generation and use that is challenged by the use of renewable energy (Pasqualetti, 1999) and embedded generation. As a consequence, the increasing prevalence of smaller-scale, embedded or distributed power systems using local energy resources, is resulting in a greater importance associated with non-technical, specifically social and psychological aspects, of energy generation, supply and consumption such as social capital and community involvement (Devine-Wright, Fleming and Chadwick, 2001).

We can classify different degrees of local embedding of energy projects by referring to existing models of community involvement, often incorporated into land-use planning analyses (e.g. Arnstein, 1969; Davidson, 1998). The most superficial example can be described as 'information-led', characterised by a situation where local people are informed of a proposed development; at this level, local people have no involvement with development other than as passive recipients of information. At another end of the spectrum, it is possible to envisage projects that are 'ownership-led' with a high degree of local control. In between these extremes, a range of positions will exist that can be described as varying degrees of 'partnership' between local people, interest groups, statutory institutions such as local authorities and private sector developers. More local or community-embedded examples of these could involve local use of energy generated by local plant, as might exist in a local district heating scheme, a 'private wire' mini-grid electricity network or generation technologies such as solar photovoltaic panels on community buildings. Economic benefits can be locally embedded through local distribution of profit generated by sales of energy or financial benefits from energy saved by efficiency activities (in common with the 'negawatt' concept of Von Weizsäcker, Lovins \& Lovins, 1998), local training and employment opportunities and local shareholding. Shareholding can also involve individuals resident outside of the local community, forming part of a more spatially dispersed 'community of interest' involved in, and supportive of, the development.

Whilst it is possible to distinguish between these varying forms of local energy projects at an abstract level, it is more difficult to identify examples where they have successfully been put into practice in the UK (Devine-Wright et al., 2001). The predominantly centralised, large-scale and asocial development ethos that has been the convention has resulted in rather superficial levels of local embedding of renewable energy projects (Hinshelwood, 2000) and this is reflected in the guidelines for best practice published by energy trade associations such as the British Wind Energy Association or the European Wind Energy Association, that omit any reference to co-management or co-ownership by local people. Exceptions to this predominant approach include wind energy development at the Findhorn Foundation Community in Scotland, the Baywind wind energy development in Cumbria and local authority-led district heating and private wire developments in Leicester, Woking and Southampton. An alternative scenario, recently developed by researchers for the Countryside Agency, noted a potential for local level renewable energy projects, such as these, to characterise $10 \%$ of the UK's renewable powered electricity supply by 2010 (Energy for Sustainable Development, BDOR, Projects in Partnership and The Planning Co-op, 2001). 
This paper describes empirical research that aimed to investigate support for local aspects of renewable energy development. At present little systematic research has been undertaken on this subject in the UK. Whilst a large number of market-research and opinion-poll type studies have been undertaken, these have tended to focus upon the acceptability of typical large-scale developments such as on-shore upland windfarms (e.g. Simon, 1996; Scottish Executive, 2000). Research studies of this type have tended to overlook more involved aspects of local energy development such as local management, ownership, supply and profit-sharing that are addressed in this paper. The context of investigation was the 'Awel Aman Tawe' project in South Wales. This is the development of a community owned wind farm at the Mynydd Uchaf mountain, in a region described as 'among the poorest, sickest and most deprived areas of Britain' (South Wales Guardian, 2000). Coal pit closures, industrial decline and agricultural crises have created valley communities steeped in poverty with high employment, poor mobility, declining local services and a damaged local environment.

In response to these problems, some concerned local residents set up a steering group in 1998 with the intention of using renewable energy development as a vehicle for local regeneration, by means of a wind farm controlled by the local community (Hinshelwood, 2000). From the outset, the steering group adopted a pro-local involvement and pro-wind energy approach, with the aim of persuading local people to feel a sense of ownership over the project and to give it their support. Part of the rationale for community ownership was to keep control of the revenue produced by sales of electricity generated by the wind turbines in order to feed profit back into the local community to remedy social, economic and environmental problems.

Having successfully solicited funding from a range of institutions over an 18 month period during 1999 and 2000, the steering group launched an extensive process of public participation between April 2000 and February 2001. Local people participated in, or were exposed to, a diverse range of consultative methods, including community discussions, coach trips to wind farms, public meetings, public workshops, open days, semi-structured interviews, surveys, school visits, posters, a website, leaflets, information sheets and videos (AAT, 2001). In parallel with this participatory process, funding was secured for a monitoring study that produced the data analysed in this study. This data is longitudinal, representing the results of data collected immediately before and after the participation process. The research focused upon:

1. The form of local energy beliefs: What levels of support existed within the local community for different dimensions of local involvement in the renewable energy project (local partnership, local profits, local energy supply and local ownership)?

2. The social structuring of local energy beliefs: What socio-demographic characteristics of local people structured the adoption of specific beliefs?

\section{Method:}

Sample:

259 people were selected from the electoral role of fourteen villages sited adjacent to the development site, targeting every $25^{\text {th }}$ person as a participant in the research. 
Structured interviews were carried out in April and May 2000, immediately prior to the public participation process and were conducted by local volunteers who had been trained by the Research Development Support Unit, University of Wales, Swansea (Awel Aman Tawe, 2001). Of these 259 interviewees, 167 participated in follow-up interviews carried out in February and March 2001 at the conclusion of the participation process, representing $65 \%$ of the original sample. Missing data was caused by a number of reasons, including 20 who refused to participate, 13 who had moved house, 4 who had died, one who had not been interviewed before and a further 53 who could not be contacted. Of this complete sample of 167, just over half the individuals were female $(\mathrm{n}=89 ; 53.3 \%)$ whilst just under half were male $(\mathrm{n}=78$; $46.7 \%$ ). The mean age was 53.4 with a range of $17-85$. In terms of employment status, $55(32.9 \%)$ responded that they worked; 98 were unemployed $(58.7 \%)$ with several others indicating disability, student status or full time homeworkers. In terms of length of residence in the local area, the sample indicated typically lengthy local residence, with an average of 40.23 years and a range of 1-85 years. The sociodemographic profile of the sample is representative of the locality at Awel Aman Tawe, in being a predominantly older and often unemployed community as a result of local economic deprivation that has led to widespread migration of younger people away from the area (Awel Aman Tawe, 2001).

\section{The survey tool:}

The survey tool was designed to measure people's beliefs about wind energy development generally and the community wind farm project specifically. The survey mixed open and closed questions and was administered on a face-to-face basis. Sociodemographic characteristics of respondents were probed, including age, gender, length of local residence and employment. Statements probed specific beliefs about local aspects of wind energy development: 'windfarms should not be developed unless they are owned by the community; windfarms should always be developed in partnership with local communities; energy produced by windfarms should be used locally; wind farms should only be developed if profits are put back into the local community'. These items had three response options (agree, disagree and not sure) and were designed to measure a number of key aspects of local energy development, including partnership working, profit share, ownership and local use of locally generated energy.

\section{Results}

Part 1: Beliefs about local aspects of wind energy measured before and after the participation process

Beliefs about local aspects of wind energy development are summarised in the table below. 'Before' refers to the pre-participation wave of interviews and 'Afterwards' to the post-participation wave of interviews. 
Table 1: Summary of agreement with four aspects of local involvement before and after the participation process

\begin{tabular}{|c|c|c|c|c|}
\hline \multicolumn{5}{|c|}{ "Wind farms should always be developed in partnership with local communities" } \\
\hline & Agree & Not sure & Disagree & Total \\
\hline Before & $142(85.5 \%)$ & $10(6 \%)$ & $14(8.4 \%)$ & 166 \\
\hline Afterwards & $146(88.5 \%)$ & $10(6.1 \%)$ & $9(5.5 \%)$ & 165 \\
\hline \multicolumn{5}{|c|}{ "Energy produced by wind farms should be used locally" } \\
\hline & Agree & Not sure & Disagree & Total \\
\hline Before & $137(82 \%)$ & $11(6.6 \%)$ & $19(11.4 \%)$ & 167 \\
\hline Afterwards & $136(82.4 \%)$ & $10(6.1 \%)$ & $19(11.5 \%)$ & 165 \\
\hline \multicolumn{5}{|c|}{ "Wind farms should only be developed if profits are put back into the local community" } \\
\hline & Agree & Not sure & Disagree & Total \\
\hline Before & $144(86.7 \%)$ & $12(7.2 \%)$ & $10(6 \%)$ & 166 \\
\hline Afterwards & $139(84.2 \%)$ & $13(7.9 \%)$ & $13(7.9 \%)$ & 165 \\
\hline \multicolumn{5}{|c|}{ "Wind farms should not be developed unless they are owned by the community" } \\
\hline & Agree & Not sure & Disagree & Total \\
\hline Before & $89(53.3 \%)$ & $43(25.7 \%)$ & $35(21 \%)$ & 167 \\
\hline Afterwards & $86(51.5 \%)$ & $53(31.7 \%)$ & $26(15.6 \%)$ & 165 \\
\hline
\end{tabular}

The table indicates that three of the aspects - local partnership, local energy use and local benefit from profits generated by a wind farm - were agreed with by the overwhelming majority of respondents. This high level of support did not vary over time, with negligible difference between before and after participation levels. Support for the statement that local ownership was a necessary condition of wind farm development was slightly lower, yet still a majority, with far higher levels of 'not sure' response to this item at both time periods in comparison to other dimensions. As with the other aspects, little change over time is illustrated by the data.

\section{Part 2: how do local energy beliefs relate to socio-demographic characteristics?}

Statistical analyses were performed to investigate the role of personal characteristics such as gender, age, employment status and length of residence in the locality upon beliefs about local wind energy development. These relations were tested at two points in time - before the participation process and afterwards. Analyses revealed no significant gender effects, indicating that males and females did not differ in their beliefs about local wind energy development either before or afterwards. In terms of age, bivariate correlations ${ }^{1}$ between respondents' age and the four aspects of local energy development mentioned above, indicated only one weak effect before the participation process had taken place - a negative relationship between age and support for local ownership (pearson's $r=-.150 ; n=167 ; p<.05$ ). This suggested that the older the respondent, the more likely that he or she was to agree, before participation processes had begun, that local ownership should be a mandatory aspect of wind energy development. 
Following up this result, further analysis was conducted to test for an interaction between age and gender in shaping public beliefs about local ownership. Results indicated an interaction effect for males and age but not for females, indicating that older males were more likely to support local ownership than younger male respondents $(\mathrm{r}=-.281 ; \mathrm{n}=78 ; \mathrm{p}=.013)$. This interaction effect is illustrated by the fact that $37 \%$ of male respondents aged under 30 supported local ownership, in contrast with 53\% aged between 30 and 50 and $63.5 \%$ aged over 50. To test whether link between age, gender and beliefs about local ownership changed over time, analysis was conducted at the second time point. This revealed no significant relation for males or females in relation to age and beliefs about local energy development. In the case of male respondents, this was because the proportion of younger men supporting local ownership increased from $37 \%$ to $47 \%$ after the participation process.

In terms of employment, analysis indicated a relation only between employment status and beliefs about local distribution of profits generated by the wind farm, using a two-tailed chi-squared probability test ${ }^{2}$ (chi-square $=7.256(\mathrm{df} 2) \mathrm{p}=0.027$ ). Before the participation process began, those not working were more likely to agree with local profit distribution in comparison to those who were in work, although results clearly indicate majority support for local profit distribution amongst both groups. The data is summarised in the following table.

Table 2: Summary of statistics indicating the link between employment status and beliefs about local distribution of profits from the wind farm

\begin{tabular}{|l|l|l|l|l|}
\hline & Agree & Not sure & Disagree & Total \\
\hline In work & $42(76 \%)$ & $8(15 \%)$ & $5(9 \%)$ & $55(100 \%)$ \\
\hline Not in work & $89(92 \%)$ & $4(4 \%)$ & $4(4 \%)$ & $97(100 \%)$ \\
\hline Total & 131 & 12 & 9 & 152 \\
\hline
\end{tabular}

Analysis for data at the post-participation time point indicated no significant difference between respondents with different employment status, although levels of support amongst those not in work was still higher ( $86 \%$ vs. $76 \%$ ), chiefly because a small number of respondents who had agreed with local profit distribution before the participation indicated 'not sure' afterwards (i.e. $4 \%(n=4)$ of respondents not in work indicated 'not sure' before the participation in comparison to $9 \%(\mathrm{n}=9)$ afterwards). Analysis for links between respondents' length of residence in the local area and their beliefs about local energy development indicated no significant relationship for each aspect at time 1 and at time 2; nor any interaction between length of residence and gender.

In summary, socio-demographic analyses indicated no gender effects overall but an interaction effect between gender, age and support for local ownership of wind energy development, with older males more likely to support local ownership. Results also indicated that socio-economic status was likely to shape beliefs about profit distribution, with those not in work more supportive in comparison to those not in work. The presence of these effects only before the participation process got underway rather than afterwards suggests that the participation process had some 
effect upon respondents' beliefs about local energy development (e.g. increasing support amongst younger men for local energy development) and that this impact was not always in a positive direction (e.g. more of those not in work unsure about the merits of local profit distribution afterwards).

\section{Discussion:}

This research study attempted to explore several gaps in the existing research literature on public beliefs about renewable energy development in the UK. This included how the public perceived and supported several local and community aspects of renewable energy development and how these beliefs were structured according to specific socio-demographic characteristics. It was noted that, despite recent public, private and voluntary sector initiatives to embed renewable energy development at local level and forecasts of a potential $10 \%$ contribution of by local renewable projects to the UK government target for renewable powered electricity by 2010 (Energy for Sustainable Development et al., 2001), little research addressing public beliefs and support for such energy projects had taken place.

The results indicate that high levels of support can exist for on-shore wind energy development that is embedded within the local community. The vast majority of respondents, randomly selected from the local community, agreed that wind farms should be developed in partnership with the local community, that local people should be able to use energy generated locally and that profits should be distributed amongst local people, with a lesser number, yet still a majority of respondents, supporting local ownership. The results suggest that proposed renewable energy developments are less likely to be controversial, and consequently that renewable energy policy targets are more likely to be met, if and when developers and statutory institutions adopt a more locally embedded approach. This could imply a basis for a greater role to be played by UK local authorities, in partnership with businesses and voluntary sector organisations, in the process of renewable energy development than is currently the case. Such a role would involve not merely having a say in development control but being involved in partnerships with local people and private sector developers to deliver local community energy projects. The lower levels of support for mandatory local ownership and high levels of support for a partnership approach suggests that respondents would be likely to support local partnerships for renewable energy development, as enshrined in recent UK initiatives such as the Community

Renewables Initiative and as employed successfully in other countries such as Denmark (Daugarrd, 1997).

Analysis according to socio-demographic characteristics indicated some interesting findings. For example, in this case-study, older men were more likely to support local ownership than younger men (although this difference was only observed before the participation process). This result must be seen in the context of the locality in which the research was undertaken. Those male respondents aged over 50 at the time of research are likely to have worked in, or to be familiar with, another energy industry: coal-mining when it was a major source of local employment in the 1970s and 1980s in South Wales. These individuals may hold political beliefs that favour ownership by workers or local people and may have witnessed industrial decline that led to the 
adoption of negative beliefs about private-sector development from outside the locality. The results suggest that further research probing links between respondent's political ideology, their memories or representations of past development in the locality, levels of trust in public and private sector organisations and their support for future local energy development would be useful.

With the impacts of climate change (IPCC, 2001), global scientists and politicians have been calling for greater levels of public awareness and understanding of energy generation and consumption (Royal Commission on Environmental Pollution, 2000), greater involvement in energy planning (Local Government Association, 1999), public engagement in an energy debate (PIU, 2002) and involvement in actual development (Department of Trade and Industry, 2003). It is argued that the centralised infrastructure fosters a spatial and psychological distance between energy generation, supply and consumption (Pasqualetti, 1999). As a consequence, it is unlikely that the public will engage with the 'invisible' concept of energy (Hedges, 1991; Guy and Shove, 2000) unless attempts are made to make it more visible, familiar and relevant to people (Walker, 1995). This research offers some empirical support for the viewpoint that a local scale approach to energy development may offer a more fruitful basis for creating a climate in which the public can become involved with, and engage in a debate about energy futures. There is, perhaps, a need to reconsider the content of industry best practice guidelines for energy development to better reflect the full scope of potential embedding of energy development at local and community level, going beyond the concept of consultation to more developed issues such as local partnership, co-management, supply and profit share.

This study attempted to address public beliefs and policy implications about local and community aspects of renewable energy development in the UK. However, one weakness of the study, as is similarly the case for most published research on public beliefs about renewable energy development in the UK, is the single case design employed. It could be argued that the Awel Aman Tawe community wind farm is being proposed in a locality that is distinctive from many other localities in the UK in terms of the degree of social, environmental and economic disadvantage that is prevalent in the locality (AAT, 2001). As such, the results may be more generalisable to others areas of disadvantage than to the UK as a whole. In part, this is likely to be true. However, the presence of a vocal minority in the locality who have bitterly opposed the development, in NIMBY-type fashion (Tairgwaith Action Group, 2003), is testimony to the fact that this distinctiveness from other locations is probably less marked than may be assumed. The high perceived regard, amongst the protesting group, for an environment that may be objectively described as scarred from opencast coal mining is testimony to the significance of subjective opinions in this area. It is certainly the case that future research is required to investigate how widely shared these beliefs are in support of local aspects of renewable energy development across locations of diverse socio-economic status.

In conclusion, the research indicated that locally embedded wind energy development can receive high and stable levels of public support. The results suggest that the adoption of this approach, as is proposed by several recent UK public, private and voluntary sector initiatives, is likely to be strongly supported by local people, thus reducing the potential for local opposition and delay common to past developments. Integrating a local or community-oriented approach, through local supply, partnership 
and profit-share, may not only enable the reaching of specific government targets for energy development and carbon emission reduction, but also help to promote a more informed basis for public debate about future patterns of energy generation and use through elevated levels of local community involvement. This has been recommended by the Royal Commission on Environmental Pollution (2000) and the recent Energy Review (PIU, 2001) and would support the achievement of the challenging UK target, conveyed in the Energy White Paper (Department of Trade and Industry, 2003), of $60 \%$ reduction in carbon emissions by 2050 to produce a low carbon society.

Acknowledgements: The author would like to acknowledge: the steering group at Awel Aman Tawe, in particular Emily Hinshelwood and Dan McCallum, for permission to access this data set and their cooperation; the contribution of local volunteers who assisted in data collection and finally, to Dr. Hannah Devine-Wright for comments on the paper.

Note 1: Bivariate correlation tests the degree of relativity between two variables and represents this on a numerical scale between -1 and 1 . When a correlation approaches -1 , this suggests that high scores on one variable coincide with low scores on the other; when +1 , high responses on one variable coincide with high responses on the other (and low with low); when a correlation approaches 0 , this indicates no linear relationship between each variable.

Note 2: A chi-squared probability test analyses whether the observed set of data differs significantly from expected set of data, based upon chance probability (e.g. 50:50 in a response set of two options).

\section{References:}

Awel Aman Tawe (2001) Examining Approaches to Renewables Consultation: Lessons from the Awel Aman Tawe Community Wind Farm Project. ETSU Report K/BD/00236/REP.

Arnstein, S.R. (1969) A Ladder of Citizen Participation, Journal of the American Planning Association, 35(4) pp. 216-224.

Department of Trade and Industry (1999) New and Renewable Energy: Prospects for the $21^{\text {st }}$ Century. (DTI: London).

Department of Trade and Industry (2003) Energy White Paper. (DTI: London).

Daugaard, N. (1997) Acceptability Study for the use of Wind Power in Denmark. (Energy Centre Denmark, Copenhagen).

Davidson, S. 1998. Spinning the wheel of empowerment. Planning, April $3^{\text {rd }}$ pp. 14-15.

Devine-Wright, P., Fleming, P.D. \& Chadwick, H. (2001) The role of social capital in advancing regional sustainable development. Impact Assessment and Project Appraisal, 19(2), 161-167

Devine-Wright, P., Fleming, P.D., Akehurst, P., Kersey J. \& Jamison, C. (2003) Consultation on Successful Carbon Emission Reduction Projects. Report produced for the Sustainable Development Commission. Available at the following website: http://www.dcarb-uk.org/ (last accessed on September $2^{\text {nd }} 2003$ )

Devine-Wright, P.; McAlpine, G. \& Bately-White, S. (2001) Wind turbines in the landscape: An evaluation of local community involvement and other considerations in UK wind farm development. 
Proceedings of the $32^{\text {nd }}$ Annual Conference of the Environmental Design Research Association, Edinburgh, Scotland, July 3-6 ${ }^{\text {th }}, 133-137$.

Dunn, P. (1978) Appropriate technology: technology with a human face. (London: Macmillan).

Energy for Sustainable Development, BDOR, Projects in Partnership and The Planning Co-op (2001) Community Based Renewable Energy: Delivering Projects in the English Countryside. Report prepared for the Countryside Agency.

Fielden, D. (2000) Decentralized Power and Biomass. Cogeneration and On-Site Power Production, May-June, pp.43-46.

Guy, S. \& Shove, E. (2000) A Sociology of Energy, Buildings and the Environment: Constructing knowledge, designing practice. (Routledge Research Global Environmental Change: London).

Hedges, A. (1991) Attitudes to Energy Efficiency in the Home: Report on a Qualitative Study. (HMSO: London).

Hinshelwood, E. (2000) Whistling in the Wind: the role of communities in renewable energy development. Network for Alternative Technology and Technology Assessment Newsletter 127 (SeptOct) pp. 17-20.

Intergovernmental Panel on Climate Change (2001) Third Assessment Report: The Scientific Basis. Available from the website: http://www.ipcc.ch/ (last accessed September $30^{\text {th }} 2003$ ).

Local Government Association (1999) Energy services for sustainable communities: the local government position. (LGA: London).

Lovins, A. (1977) Soft Energy Paths. (Penguin: London).

Pasqualetti, M.J. (1999) Morality, Space, and the Power of Wind-Energy Landscapes. The Geographical Review, 90(3) pp. 381-394

Patterson, W. (1999) Transforming Electricity. (Royal Institute of International Affairs/Earthscan: London).

Performance and Innovation Unit (2002) The Energy Review. (HMG Cabinet Office: London).

Rakos, C. (1998) Lessons Learned from the introduction of Biomass District Heating in Austria. (E.V.A., Austrian Energy Agency: Vienna, Austria).

RENEW (2002) UK wind: still pushing ahead. Network for Alternative Technology and Technology Assessment Newsletter 140 (Nov-Dec) p9.

Royal Commission on Environmental Pollution (2000) Energy - the Changing Climate. (Royal Commission on Environmental Pollution: London).

Schumacher, E.P. (1974) Small is beautiful. (Sphere Books: London).

Schweizer-Ries, P., Casper, C., Djuwita, R., Ramirez, E., Hidalgo de Avila, E. (2001) Social interventions to achieve success with off-grid village power supply systems: Case studies from Indonesia, Spain and Argentina. Proceedings of the $17^{\text {th }}$ European Photovoltaic, Solar Energy Conference, Munich, Germany, 22-26 October, pp. 1951-1955.

Scottish Executive Central Research Unit. Public Attitudes Towards Wind Farms in Scotland. Edinburgh, Scottish Executive, 2000. 
Simon AM. A Summary of Research Conducted into Attitudes to Wind Power from 1990-1996. British Wind Energy Association, 1996. [Online]. Available: www.bwea.com/ref/survey.html, Accessed on January $4^{\text {th }} 2003$.

South Wales Guardian (15 ${ }^{\text {th }}$ February 2001) Bitter wind farm row blows up. In Awel Aman Tawe (2001) Examining Approaches to Renewables Consultation: Lessons from the Awel Aman Tawe Community Wind Farm Project. ETSU Report K/BD/00236/REP.

Tairgwaith Action Group (2003) Information available at the following website http://www.geocities.com/tairgwaithactiongroup/ (last accessed September 30 ${ }^{\text {th }} 2003$ )

Von Weizsäcker, E., Lovins, A.B. \& Lovins, L.H. (1998) Factor four: doubling wealth - halving resource use: the new report to the Club of Rome. (Earthscan: London).

Walker, G. (1995) Renewable Energy and the Public. Land Use Policy, 12(1) pp. 49-59. 